\title{
Risk factors for cisplatin-induced acute kidney injury: A pilot study on the usefulness of genetic variants for predicting nephrotoxicity in clinical practice
}

\author{
HIROYASU ODA $^{1 *}$, TOSHIRO MIZUNO ${ }^{1 *}$, MAKOTO IKEJIRI $^{2,3}$, MAKI NAKAMURA $^{2,3}$, \\ AKIRA TSUNODA $^{1}$, MIKIYA ISHIHARA ${ }^{1}$, KANAKO SAITO $^{1}$, SATOSHI TAMARU $^{1}$, YOSHIKI YAMASHITA ${ }^{1}$, \\ YUHEI NISHIMURA $^{4}$, KANAME NAKATANI ${ }^{2,3}$ and NAOYUKI KATAYAMA ${ }^{1}$ \\ Departments of ${ }^{1}$ Medical Oncology, ${ }^{2}$ Clinical Laboratory, ${ }^{3}$ Genomic Medicine and ${ }^{4}$ Integrative \\ Pharmacology, Mie University Graduate School of Medicine, Tsu, Mie 5148507, Japan
}

Received January 9, 2020; Accepted July 1, 2020

DOI: $10.3892 / \mathrm{mco} .2020 .2127$

\begin{abstract}
Several studies have reported risk factors for predicting cisplatin-induced acute kidney injury (AKI), including old age, female sex, smoking, hypoalbuminemia, hypokalemia, hypomagnesemia, a high body surface area, advanced cancer and the total dose of cisplatin administered. Recently, some studies have focused on the associations between genetic alterations in the genes coding for renal drug transporters, such as organic cation transporter 2 (OCT2), and the nephrotoxicity of cisplatin. However, genetic variants have not been fully elucidated for clinical use. Patients who had received cisplatin $\left(\geq 50 \mathrm{mg} / \mathrm{m}^{2}\right)$-containing chemotherapy as a first-line treatment were considered as eligible for the present study. The occurrence of AKI and its associations with baseline characteristics, conventional biomarkers and single-nucleotide variants (SNV) were assessed. AKI was defined as an increase in the serum creatinine level of $>0.3 \mathrm{mg} / \mathrm{dl}$ or to 1.5-2 times the baseline level. Genotyping was conducted using the DMET platform (DMET Plus), which characterizes 1,936 genetic variants (1,931 SNV and 5 copy number variations) in 231 genes. Between April 2014 and June 2016, a total of 28 patients ( 22 men and 6 women) were enrolled. AKI occurred in 8 of the 28 enrolled patients (28.6\%). Univariate analyses demonstrated that the urinary $\beta 2$-microglobulin level and body surface area were significantly higher in the AKI group $(\mathrm{P}<0.05)$. As regards the associations between AKI and $\mathrm{SNV}$, none of the examined SNV were found to be associated
\end{abstract}

Correspondence to: Dr Toshiro Mizuno, Department of Medical Oncology, Mie University Graduate School of Medicine, 2-174 Edobashi, Tsu, Mie 5148507, Japan

E-mail: tomizuno@clin.medic.mie-u.ac.jp

${ }^{*}$ Contributed equally

Key words: cisplatin, acute kidney injury, nephrotoxicity, risk factor, single-nucleotide variants with cisplatin-induced AKI. The findings of the present study suggested that certain clinical factors were associated with the onset of AKI, but no associations were identified with genetic factors, including OCT2. Although this was a small pilot study, the findings indicated that genetic factors may not be of value for predicting AKI in clinical practice.

\section{Introduction}

Cisplatin is a cytotoxic agent, which is used to treat a variety of neoplasms. While the toxicities of cisplatin include emesis, loss of appetite, ototoxicity and peripheral neuropathy, the main dose-limiting side effect of cisplatin is nephrotoxicity. Several studies have reported risk factors for predicting cisplatin-induced acute kidney injury (AKI), such as old age, female sex, smoking, hypoalbuminemia, hypokalemia, hypomagnesemia, a high body surface area, the frequency of cisplatin treatment, the combined use of cisplatin and paclitaxel, advanced cancer, the total dose of cisplatin administered, cardiovascular disease and diabetes mellitus (1-6).

Recently, some studies have focused on the associations between genetic alterations in the genes coding for renal drug transporters, such as organic cation transporter 2 (OCT2), and the nephrotoxicity of cisplatin (7-10). One of the problems with these studies on genetic variants is that their analyses are based on several different definitions of renal injury. In clinical practice, the measurement of serum creatinine concentration is widely used for the detection of AKI. Therefore, the usefulness of genetic information must also be verified using a widely accepted definition of renal damage, such as that included in the National Cancer Institute-Common Terminology Criteria for Adverse Events (NCI-CTCAE).

The aim of the present pilot study was to elucidate the usefulness of genetic variants in predicting AKI using serum creatinine measurements.

\section{Materials and methods}

Study design and participants. This was a single-center pilot study. Patients were selected for this study according 
to the following criteria: i) Administration of cisplatin $\left(\geq 50 \mathrm{mg} / \mathrm{m}^{2}\right)$-containing chemotherapy as first-line treatment; ii) creatinine clearance rate (CCR) of $\geq 50 \mathrm{ml} / \mathrm{min}$ and a normal serum creatinine level; iii) Eastern Cooperative Oncology Group (ECOG) performance status score of 0-2; iv) adequate organ function, and v) age $\geq 20$ years. The exclusion criteria were as follows: Uncontrolled hypertension, diabetes mellitus, hyperuricemia, pleural effusion and/or ascites that required drainage to reduce the associated symptoms, and a history of previous treatment with cisplatin-containing chemotherapy.

The present study was conducted in accordance with the principles outlined in the Declaration of Helsinki and the International Conference on Harmonization and Good Clinical Practice guidelines. The study protocol was approved by the Institutional Ethics Committee of Mie University Hospital (approval no. 2721). All the patients provided written informed consent.

Procedures. All the cisplatin-containing regimens were administered in the inpatient setting. Cisplatin was administered in $500 \mathrm{ml}$ of $0.9 \%$ normal saline over $2 \mathrm{~h}$. All patients were pre- and posthydrated with infusions of $\geq 1,000 \mathrm{ml}$ of saline. For antiemetic prophylaxis, $5-\mathrm{HT}_{3}$ serotonin receptor antagonists and dexamethasone were administered 15-30 min before the start of the cisplatin treatment, and a neurokinin 1 receptor antagonist was administered 60 min before the start of cisplatin treatment in all cases. Laboratory testing (hematological, serological and urological tests) were conducted at baseline (days -5-0) and on days 2-4, 7-9, 12-18 and 19-25 after chemotherapy.

For the genetic analysis, genomic DNA samples were isolated from blood samples using the Qiagen DNA isolation kit (Qiagen $\mathrm{GmbH})$ and quantified using a NanoDrop spectrophotometer at $260 \mathrm{~nm}$ (Thermo Fisher Scientific, Inc.). The samples were genotyped using the DMET platform (DMET ${ }^{\mathrm{TM}}$ Plus, Affymetrix; Thermo Fisher Scientific, Inc.) according to the standard protocol described by the manufacturer. The DMET Plus GeneChip enables the genotyping of 1,936 functionally significant genetic variants [1,931 single-nucleotide variants (SNV) and 5 copy number variations] in 231 genes, including phase I and II drug-metabolizing enzyme-coding genes and drug transporter-coding genes. The DMET Plus platform examines various types of genetic variations, including biallelic and triallelic SNV, copy number variations and insertions/deletions, and includes efficient and comprehensive molecular inversion probe technology. Then, a genotype profile for the 1,931 SNV was generated using the DMET ${ }^{\mathrm{TM}}$ console, v1.3 (Affymetrix; Thermo Fisher Scientific, Inc.).

Outcomes. In accordance with previous studies (1-14), cisplatin-induced nephrotoxicity was evaluated based on two definitions.

AKI as defined by CTCAE v4.0. In terms of the clinical-practical aspects, AKI is defined as an increase in the serum creatinine level of $>0.3 \mathrm{mg} / \mathrm{dl}$ or to $1.5-2$ times the baseline level with reference to the NCI-CTCAE v4.0.

Changes in estimated glomerular filtration rate (eGFR). Several previous studies on genetic factors have adopted changes in the eGFR as outcomes $(7,11,12)$. Therefore, regarding genetic variants that are considered to be associated with renal impairment, we evaluated not only their associations with AKI (CTCAE v4.0), but also their effect on the mean changes from baseline eGFR after the first cycle of chemotherapy.

Statistical analysis. The patients' baseline characteristics, including information on age, sex, ECOG performance status, height, weight, body mass index, body surface area, complications, smoking history, site of the primary tumor, tumor histology, clinical stage, combination chemotherapy, concurrent radiotherapy, laboratory data and SNV, were recorded. Two-sided Student's t-test, Mann-Whitney U test, or Fisher's exact test were used to compare the baseline characteristics of the groups with and without cisplatin-induced AKI. All statistical analyses were performed with IBM SPSS statistics v23.0 (IBM Corp.). All P-values were two-sided, and $\mathrm{P}<0.05$ was considered to indicate statistically significant differences.

To identify genetic variants that were associated with the changes in eGFR, each genotype of every genetic variant was first converted to numerical values as follows: $\mathrm{A} / \mathrm{A}$ to $1, \mathrm{~A} / \mathrm{C}$ to 2, $\mathrm{A} / \mathrm{G}$ to $3, \mathrm{~A} / \mathrm{T}$ to $4, \mathrm{C} / \mathrm{C}$ to $5, \mathrm{C} / \mathrm{G}$ to $6, \mathrm{C} / \mathrm{T}$ to $7, \mathrm{G} / \mathrm{G}$ to $8, \mathrm{G} / \mathrm{T}$ to 9 and $\mathrm{T} / \mathrm{T}$ to 10 . We then converted the quantitative values to $\mathrm{Z}$ scores, based on the mean and standard deviation values for patients with each SNV. The changes in eGFR (difference between the minimum value and the baseline value) were also converted to $\mathrm{Z}$ scores based on the mean and standard deviation values for each endpoint. The SNVs associated with the changes in eGFR were identified using Pavlidis Template Matching in the TM4 MeV package $(15,16)$ using $\mathrm{P}<0.05$ as a threshold.

\section{Results}

Baseline characteristics. A total of 28 patients ( 22 men and 6 women) were enrolled in this trial between April 2014 and June 2016. The baseline characteristics of the patients are listed in Table I. Their median age was 65 years (range, 55-77 years). All the patients had a good performance status (0 or 1$)$ according to the ECOG scale. A total of 13 patients (46.4\%) had hypertension and 8 (28.6\%) patients had diabetes mellitus. A total of $23(82.1 \%)$ patients had a history of smoking. The predominant primary tumor site was the esophagus (75\%). The other primary tumor sites included the stomach in 4 cases (14.3\%), the lungs in 2 cases (7.1\%) and the pancreas in 1 case (3.6\%). The predominant histological type was squamous cell carcinoma (60.7\%). There were 7 cases $(25 \%)$ of adenocarcinoma, and 4 cases $(14.3 \%)$ of neuroendocrine carcinoma. A total of 11 patients $(39.3 \%)$ received cisplatin as neoadjuvant or adjuvant chemotherapy, 15 (53.6\%) received cisplatin as palliative chemotherapy and $2(7.1 \%)$ received cisplatin as concurrent chemoradiotherapy. The median serum creatinine level was $0.73 \mathrm{mg} / \mathrm{dl}$, the median eGFR was $82.3 \mathrm{ml} / \mathrm{min} / 1.73 \mathrm{~m}^{2}$, and the median CCR was $88.1 \mathrm{ml} / \mathrm{min}$.

Incidence of AKI. AKI, as defined by CTCAE v4.0, occurred in $10 / 28$ patients (35.7\%). Of these 10 patients with AKI, 2 suffered ileus or vomiting during chemotherapy. As such adverse events can cause pre-renal injuries, these 2 patients were excluded from our analysis. In total, 8 patients (28.6\%) developed cisplatin-induced AKI, whereas 18 patients (64.2\%) had no indications of cisplatin-induced AKI. A comparison of various parameters in 
Table I. Baseline characteristics of the patients.

\begin{tabular}{|c|c|}
\hline Characteristics & No. $(\%)$ \\
\hline Age (years), median (range) & $65(55-77)$ \\
\hline \multicolumn{2}{|l|}{ Sex } \\
\hline Male & $22(78.6)$ \\
\hline Female & $6(21.4)$ \\
\hline \multicolumn{2}{|l|}{ ECOG performance status score } \\
\hline 0 & $9(32.1)$ \\
\hline 1 & $19(67.9)$ \\
\hline \multicolumn{2}{|l|}{ Predominant primary tumor site } \\
\hline Esophagus & $21(75.0)$ \\
\hline Stomach & $4(14.3)$ \\
\hline Pancreas & $1(3.6)$ \\
\hline Lung & $2(7.1)$ \\
\hline \multicolumn{2}{|l|}{ Predominant histological type } \\
\hline Squamous cell carcinoma & $17(60.7)$ \\
\hline Adenocarcinoma & $7(39.3)$ \\
\hline Neuroendocrine carcinoma & $4(14.3)$ \\
\hline \multicolumn{2}{|l|}{ Setting } \\
\hline Neoadjuvant/adjuvant & $11(39.3)$ \\
\hline Metastatic & $15(53.6)$ \\
\hline Concurrent chemoradiotherapy & $2(2.7)$ \\
\hline \multicolumn{2}{|l|}{ Co-administered drugs } \\
\hline Fluorouracil & $20(71.4)$ \\
\hline Etoposide & $4(14.3)$ \\
\hline S-1 & $3(10.7)$ \\
\hline Pemetrexed & $1(3.6)$ \\
\hline Cisplatin dose $\left(\mathrm{mg} / \mathrm{m}^{2}\right)$, median (range) & $70(60-80)$ \\
\hline Creatinine (mg/dl), median (range) & $0.73(0.40-0.99)$ \\
\hline eGFR $\left(\mathrm{ml} / \mathrm{min} / 1.73 \mathrm{~m}^{2}\right)$, median (range) & $82.3(61.2-142.5)$ \\
\hline $\begin{array}{l}\text { Creatinine clearance }(\mathrm{ml} / \mathrm{min}) \\
\text { median (range) }\end{array}$ & $88.1(50.0-206)$ \\
\hline \multicolumn{2}{|l|}{ Comorbidities } \\
\hline Hypertension & $13(46.4)$ \\
\hline Diabetes & $8(28.6)$ \\
\hline \multicolumn{2}{|l|}{ History of smoking } \\
\hline Yes & $23(82.1)$ \\
\hline No & $5(17.9)$ \\
\hline
\end{tabular}

eGFR, estimated glomerular filtration rate; ECOG, Eastern Cooperative Oncology Group.

terms of the presence or absence of AKI is presented in Table II. The patients' median age and the median dosage of cisplatin were similar between the two groups. The pretreatment CCR of the patients with AKI was similar to that of patients without AKI. In the present study, the majority of the patients developed AKI on days 7-9. Among the 8 patients with AKI, the serum creatinine levels of 6 patients subsequently returned to normal, whereas 2 patients developed irreversible renal failure.

Risk factors

Clinical factors. Univariate analyses were used to identify clinical risk factors for cisplatin-induced AKI. The results
Table II. Comparison of the baseline characteristics of the patients with and without AKI.

\begin{tabular}{|c|c|c|}
\hline Characteristics & $\mathrm{AKI}^{+}(\mathrm{n}=8)$ & $\mathrm{AKI}^{-}(\mathrm{n}=18)$ \\
\hline $\begin{array}{l}\text { Age (years), } \\
\text { median (range) }\end{array}$ & $66(57-76)$ & $63(55-77)$ \\
\hline \multicolumn{3}{|l|}{ Sex, n $(\%)$} \\
\hline Male & $7(87.5)$ & $13(72.2)$ \\
\hline Female & $1(12.5)$ & $5(27.8)$ \\
\hline \multicolumn{3}{|l|}{$\begin{array}{l}\text { ECOG performance } \\
\text { status score, } \mathrm{n}(\%)\end{array}$} \\
\hline 0 & $4(50.0)$ & $4(22.2)$ \\
\hline 1 & $4(50.0)$ & $14(77.8)$ \\
\hline \multicolumn{3}{|l|}{ Tumor location, n (\%) } \\
\hline Esophagus & $5(62.5)$ & $15(83.3)$ \\
\hline Stomach & $2(25.0)$ & $1(5.6)$ \\
\hline Pancreas & $1(12.5)$ & $0(0)$ \\
\hline Lung & $0(0.0)$ & $2(11.1)$ \\
\hline \multicolumn{3}{|l|}{$\begin{array}{l}\text { Co-administered } \\
\text { drugs, n }(\%)\end{array}$} \\
\hline Fluorouracil & $4(50.0)$ & $15(83.3)$ \\
\hline Etoposide & $2(25.0)$ & $2(11.1)$ \\
\hline S-1 & $2(25.0)$ & $0(0.0)$ \\
\hline Pemetrexed & $0(0.0)$ & $1(5.6)$ \\
\hline $\begin{array}{l}\text { Cisplatin dose }\left(\mathrm{mg} / \mathrm{m}^{2}\right), \\
\text { median (range) }\end{array}$ & $80(60-80)$ & $80(75-80)$ \\
\hline $\begin{array}{l}\text { Creatinine (mg/dl), } \\
\text { median (range) }\end{array}$ & $0.79(0.40-0.93)$ & $0.68(0.40-0.99)$ \\
\hline $\begin{array}{l}\mathrm{CCR}(\mathrm{ml} / \mathrm{min}), \\
\text { median (range) }\end{array}$ & $81.7(61.2-116.9)$ & $89.2(50-206.2)$ \\
\hline
\end{tabular}

AKI, acute kidney injury; CCR, creatinine clearance rate; ECOG, Eastern Cooperative Oncology Group.

of the univariate analyses demonstrated that the baseline urinary $\beta 2$-microglobulin level and body surface area were significantly higher in the AKI group ( $\mathrm{P}<0.05$; Table III). In addition, the baseline serum cystatin $\mathrm{C}$ level and the baseline urinary levels of $\mathrm{N}$-acetyl- $\beta$-D-glucosaminidase and chloride were slightly higher in patients with AKI compared with those in patients without AKI. Other clinical factors, such as the serum levels of albumin, potassium and magnesium, as well as age, which have previously been reported as risk factors for cisplatin-induced AKI, were not found to be significantly associated with cisplatin-induced AKI in the present study.

Genetic factors. In genetic analysis of the associations between AKI and genetic variants, none of the examined genetic variants were found to be associated with cisplatin-induced AK. OCT2 rs316019, which was considered to be representative of renal injury-related genetic factors, was not associated with cisplatin-induced AKI ( $\mathrm{P}=0.667$, Fisher's exact test). Similarly, none of the other examined OCT2 gene variants were found to be associated with AKI. 
Table III. Clinical risk factors for AKI.

\begin{tabular}{|c|c|c|c|}
\hline Factors & $\begin{array}{c}\mathrm{AKI}^{+} \\
(\text {mean } \pm \mathrm{SD})\end{array}$ & $\begin{array}{c}\mathrm{AKI}^{-} \\
(\text {mean } \pm \mathrm{SD})\end{array}$ & P-value \\
\hline Urinary $\beta 2$-microglobulin, $\mu \mathrm{g} / \mathrm{l}$ & $730.0 \pm 888.0$ & $150.7 \pm 189.5$ & 0.016 \\
\hline Body surface area, $\mathrm{m}^{2}$ & $1.6 \pm 0.11$ & $1.5 \pm 0.12$ & 0.022 \\
\hline Cystatin C, mg/l & $1.1 \pm 0.26$ & $0.93 \pm 0.12$ & 0.075 \\
\hline Urinary chloride, $\mathrm{mEq} / \mathrm{l}$ & $134.5 \pm 54.0$ & $101.0 \pm 41.6$ & 0.097 \\
\hline Urinary NAG, U/gCrea & $15.2 \pm 12.2$ & $12.5 \pm 15.1$ & 0.107 \\
\hline Uric acid, mg/dl & $5.5 \pm 1.3$ & $4.5 \pm 1.3$ & 0.114 \\
\hline Urinary sodium, mEq/l & $132.6 \pm 34.5$ & $105.5 \pm 38.8$ & 0.134 \\
\hline Creatinine, $\mathrm{mg} / \mathrm{dl}$ & $0.76 \pm 0.16$ & $0.67 \pm 0.16$ & 0.203 \\
\hline Sodium, $\mathrm{mEq} / \mathrm{l}$ & $141.1 \pm 1.1$ & $139.2 \pm 3.8$ & 0.208 \\
\hline $\mathrm{eGFR}, \mathrm{ml} / \mathrm{min}$ & $78.6 \pm 16.04$ & $88.5 \pm 19.7$ & 0.226 \\
\hline Urinary $\alpha 1$-microglobulin, $\mathrm{mg} / \mathrm{l}$ & $7.8 \pm 6.7$ & $5.2 \pm 5.0$ & 0.289 \\
\hline Chloride, $\mathrm{mEq} / \mathrm{l}$ & $104.5 \pm 2.5$ & $102.7 \pm 3.6$ & 0.300 \\
\hline Age, years & $66.2 \pm 5.4$ & $64.0 \pm 5.5$ & 0.347 \\
\hline Urinary albumin, mg/gCrea & $175.2 \pm 469.5$ & $17.1 \pm 39.6$ & 0.373 \\
\hline Creatinine clearance, $\mathrm{ml} / \mathrm{min}$ & $84.8 \pm 22.3$ & $95.2 \pm 33.8$ & 0.487 \\
\hline Phosphorus, mg/dl & $3.3 \pm 0.47$ & $3.1 \pm 0.49$ & 0.546 \\
\hline Urinary potassium, $\mathrm{mEq} / \mathrm{l}$ & $38.8 \pm 29.0$ & $33.7 \pm 19.8$ & 0.602 \\
\hline Potassium, $\mathrm{mEq} / \mathrm{l}$ & $4.0 \pm 0.34$ & $4.1 \pm 0.42$ & 0.628 \\
\hline Magnesium, mg/dl & $2.0 \pm 0.21$ & $2.0 \pm 0.17$ & 0.64 \\
\hline Urinary creatinine, $\mathrm{mg} / \mathrm{dl}$ & $106.1 \pm 54.8$ & $122.8 \pm 121.6$ & 0.717 \\
\hline Blood urea nitrogen, $\mathrm{mg} / \mathrm{dl}$ & $12.1 \pm 4.3$ & $12.6 \pm 5.2$ & 0.804 \\
\hline Calcium, $\mathrm{mg} / \mathrm{dl}$ & $9.4 \pm 0.85$ & $9.3 \pm 0.98$ & 0.865 \\
\hline Albumin, g/dl & $3.6 \pm 0.50$ & $3.5 \pm 0.35$ & 0.975 \\
\hline Urinary calcium, mg/dl & $13.6 \pm 6.7$ & $15.4 \pm 13.3$ & 1.000 \\
\hline
\end{tabular}

AKI, acute kidney injury; SD, standard deviation; NAG, $N$-acetyl- $\beta$-D-glucosaminidase; eGFR, estimated glomerular filtration rate.

By contrast, as regards the associations between the mean changes in eGFR and SNV, 5 SNVs (ABCC4 rs3742106, CYP7A1 rs13251066,CYP39A1 rs7761731, MAT1A rs17102596 and UGT1A $3 * 4$ rs45625338) were found to be associated with the mean changes in eGFR (Fig. 1).

\section{Discussion}

Cisplatin has been widely used as a cytotoxic agent to treat several solid tumors, such as esophageal, gastric, ovarian and lung cancer. However, other platinum-based drugs, such as carboplatin and oxaliplatin, have recently become standard treatments for these diseases; therefore, cisplatin is used less frequently than before. The main reason for avoiding to use cisplatin is its adverse effects, particularly because it is highly emetic and nephrotoxic. Nausea and vomiting are serious adverse events that affect the quality of life of patients during treatment with cisplatin-containing regimens (17). However, recent advances in antiemetic therapies, such as $5-\mathrm{HT}_{3}$ antagonists, aprepitant and olanzapine, appear to have resolved these problems (17). With regards to carboplatin and oxaliplatin, there appear to be three main limitations to their use: Hypersensitivity reactions, thrombocytopenia and peripheral neuropathy (18). Thus, determining the risk factors for cisplatin nephrotoxicity would assist clinicians in selecting patients for cisplatin-based chemotherapy among those who are not medically fit to receive carboplatin or oxaliplatin, which would be clinically significant.

In the present study, univariate analyses revealed significant differences in body surface area and pretreatment urinary $\beta 2$-microglobulin levels between the patients who did and did not develop AKI. By contrast, none of the SNVs that were previously described as risk factors for renal injuries, including OCT2, were found to be associated with AKI (CTCAE 4.0). Although this is a small pilot study, the results indicate that genetic factors may not be useful for predicting AKI as defined by CTCAE in clinical practice.

Previous studies investigating the associations between genetic variants and renal injuries, defined changes in eGFR $(7,11,12)$, cystatin C (8) and KIM-1 (13) as kidney injury. In the present study, we found that some gene variants, including $\mathrm{ABCC}$, which is involved in drug transport in kidney tubular cells, were significantly associated with mean changes in eGFR. Cystatin C and KIM-1 may be useful for early and accurate detection of kidney injury; however, these novel biomarkers require further investigation.

To apply nephrotoxicity-related genetic information to clinical decision-making, a study with an appropriate definition of nephrotoxicity, such as that defined by the CTCAE, is required. Another approach is to construct a risk 
A

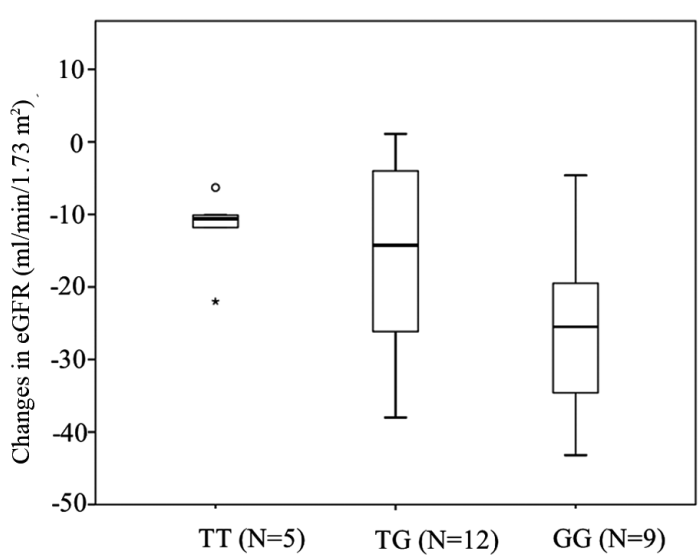

C

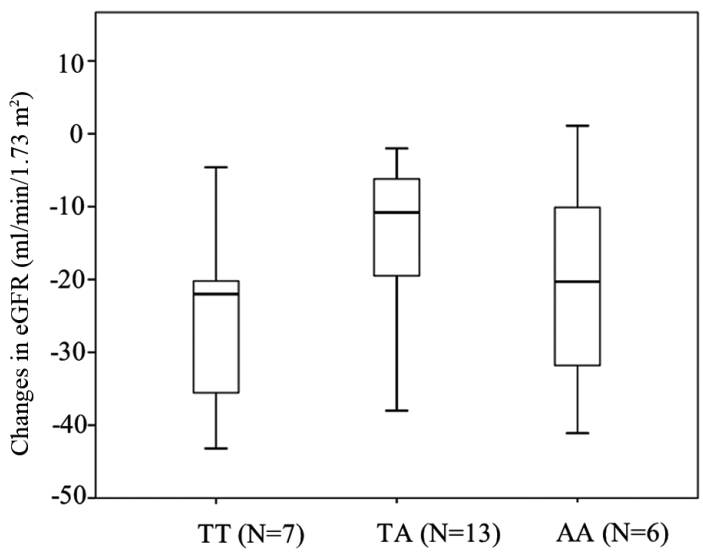

$\mathbf{E}$

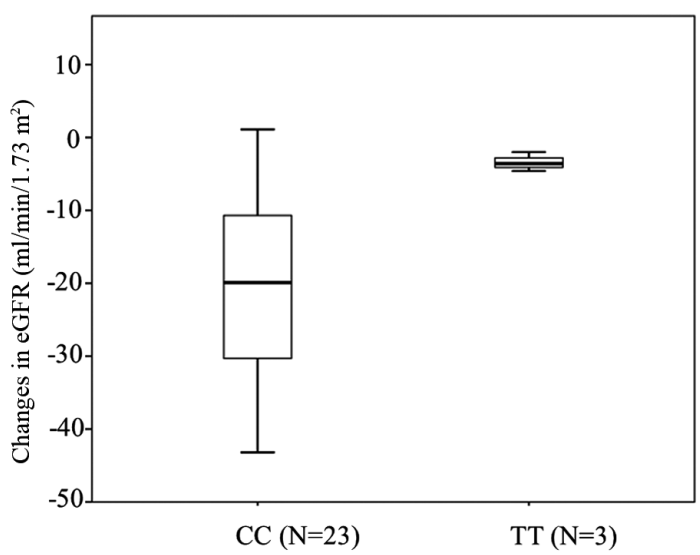

B

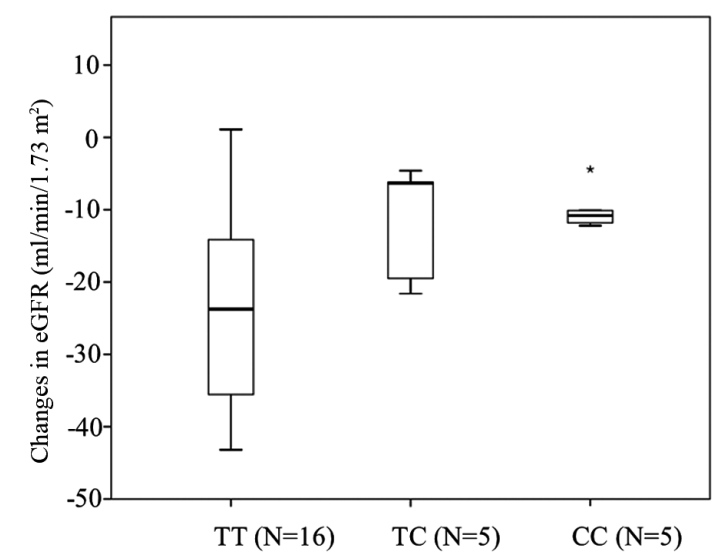

D

rs17102596 MAT1A c.769-218A>G

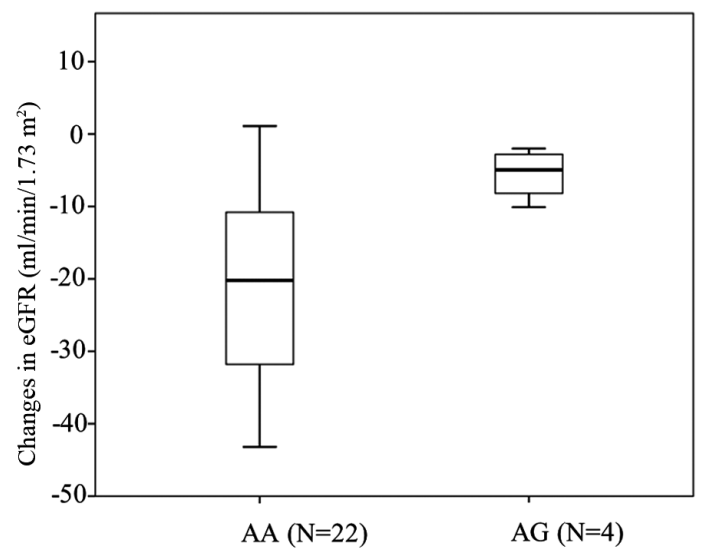

Figure 1. Associations between SNV and mean changes in the eGFR. (A) The mean change in the eGFR was significantly associated with rs3742106; ABCC4 c. $38 \mathrm{~T}>\mathrm{G}$ (TT vs. GG, P=0.048), (B) rs13251066; CYP7A1 c.-5096T>C (TT vs. CC, $\mathrm{P}=0.002$ ), (C) rs7761731; CYP39A1 c.972T>A (TT vs. TA, P=0.034), (D) rs17102596; MAT1A c.769-218A >G (AA vs. AG, P<0.001), and (E) rs45625338; UGT1A3*4 c.133C $>$ T (CC vs. TT, P<0.001). Asterisks indicate extreme outliers (greater than three times the height of the boxes). SNV, single-nucleotide variant; eGFR, estimated glomerular filtration rate.

prediction model that combines genetic variants with clinical factors. Several studies on genetic factors associated with adverse drug reactions to various antitumor drugs have been reported (19-21). Unfortunately, the prediction of adverse events based on genetic variants has not been sufficiently incorporated into daily clinical practice; however, there are some exceptions, such as the association between variants in the UGT1A1 gene and the effects of irinotecan. Considering the current situation, a risk prediction model that integrates clinical and genetic factors may be a practical approach to using genetic information in daily clinical practice.

In summary, we herein performed a pilot study to elucidate the clinical usefulness of genetic factors for predicting renal damage, with the intend of examining the associations between cisplatin-induced AKI and genetic factors in a large-scale study with an appropriate definition of nephrotoxicity. 


\section{Acknowledgements}

The authors would like to thank Professor Masahiro Okuda (Department of Pharmacy, Mie University Hospital), Mr. Kenji Ikemura (Department of Pharmacy, Mie University Hospital) and Dr Eiji Ishikawa (Department of Nephrology, Mie University Hospital), whose comments/suggestions helped improve this study.

\section{Funding}

Funding was received from Mie University Hospital, Tsu, Japan (The Director Research Grant in 2017).

\section{Availability of data and materials}

The datasets used during the present study are available from the corresponding author upon reasonable request.

\section{Authors' contributions}

HO designed the study and wrote the initial draft of the manuscript. TM contributed to interpretation of data, and assisted in the preparation of the manuscript. MaI, MN, YN and $\mathrm{KN}$ contributed to analysis and interpretation of data. HO, AT, MiI, KS, ST and YY contributed to clinical treatment. NK supervised the patient treatment. All authors critically reviewed the manuscript and approved the final version of the manuscript.

\section{Ethic approval and consent to participate}

This article does not contain any studies with animals performed by any of the authors. The study was conducted in accordance with the principles of the Declaration of Helsinki and the International Conference on Harmonization and Good Clinical Practice guidelines. The study protocol was approved by the Institutional Review Board of Mie University Hospital. Informed consent was obtained from all subjects.

\section{Patient consent for publication}

Not applicable.

\section{Competing interests}

All the authors declare that they have no competing interests.

\section{References}

1. Pabla N and Dong Z: Cisplatin nephrotoxicity: Mechanisms and renoprotective strategies. Kidney Int 73: 994-1007, 2008.

2. Perazella MA and Moeckel GW: Nephrotoxicity from chemotherapeutic agents: Clinical manifestations, pathobiology and prevention/therapy. Semin Nephrol 30: 570-581, 2010.

3. Didier Portilla, A Mazin Safar and Melissa L Shannon: Cisplatin nephrotoxicity. Post TW, ed. UpToDate. Waltham, MA: UptoDate Inc. https://www.uptodate.com/contents/cisplatinnephrotoxicity. Accessed February 26, 2019.

4. Dobyan DC, Levi J, Jacobs C, Kosek J and Weiner MW: Mechanism of cis-platinum nephrotoxicity: II. Morphologic observations. J Pharmacol Exp Ther 213: 551-556, 1980.

5. Sobrero A, Guglielmi A, Aschele C and Rosso R: Current strategies to reduce cisplatin toxicity. J Chemother 2: 3-7, 1990.
6. de Jongh FE, van Veen RN, Veltman SJ, de Wit R, van der Burg ME, van den Bent MJ, Planting AS, Graveland WJ, Stoter G and Verweij J: Weekly high-dose cisplatin is a feasible treatment option: Analysis on prognostic factors for toxicity in 400 patients. Br J Cancer 88: 1199-1206, 2003.

7. Hinai Y, Motoyama S, Niioka T and Miura M: Absence of effect of SLC22A2 genotype on cisplatin-induced nephrotoxicity in oesophageal cancer patients receiving cisplatin and 5-fluorouracil: Report of results discordant with those of earlier studies. J Clin Pharm Ther 38: 498-503, 2013.

8. Zhang J and Zhou W: Ameliorative effects of SLC22A2 gene polymorphism $808 \mathrm{G} / \mathrm{T}$ and cimetidine on cisplatin-induced nephrotoxicity in Chinese cancer patients. Food Chem Toxicol 50: 2289-2293, 2012.

9. Iwata K, Aizawa K, Kamitsu S, Jingami S, Fukunaga E, Yoshida M, Yoshimura M, Hamada A and Saito H: Effects of genetic variants in SLC22A2 organic cation transporter 2 and SLC47A1 multidrug and toxin extrusion 1 transporter on cisplatin-induced adverse events. Clin Exp Nephrol 16: 843-851, 2012.

10. Filipski KK, Mathijssen RH, Mikkelsen TS, Schinkel AH and Sparreboom A: Contribution of organic cation transporter 2 (OCT2) to cisplatin-induced nephrotoxicity. Clin Pharmacol Ther 86: 396-402, 2009.

11. Tzvetkov MV, Behrens G, O'Brien VP, Hohloch K, Brockmöller J and Benöhr P: Pharmacogenetic analyses of cisplatin-induced nephrotoxicity indicate a renoprotective effect of ERCC1 polymorphisms. Pharmacogenomics 12: 1417-1427, 2011.

12. Windsor RE, Strauss SJ, Kallis C, Wood NE and Whelan JS: Germline genetic polymorphisms may influence chemotherapy response and disease outcome in osteosarcoma: A pilot study. Cancer 118, 1856-1867, 2012

13. Chang C, Hu Y, Hogan SL, Mercke N, Gomez M, O'Bryant C, Bowles DW, George B, Wen X, Aleksunes LM and Joy MS: Pharmacogenomic variants may influence the urinary excretion of novel kidney injury biomarkers in patients receiving cisplatin. Int J Mol Sci 18: 1333, 2017.

14. Zazuli Z, Vijverberg S, Slob E, Liu G, Carleton B, Veltman J, Baas P, Masereeuw R and Maitland-van der Zee AH: Genetic variations and cisplatin nephrotoxicity: A systematic review. Front Pharmacol 9: 1111, 2018.

15. Pavlidis P and Nobel WS: Analysis of strain and regional variation in gene expression in mouse brain. Genome Biol 2: Research0042, 2001.

16. Howe EA, Sinha R, Schlauch D and Quackenbush J: RNA-Seq analysis in MeV. Bioinformatics 27: 3209-3210, 2011.

17. Hesketh PJ, Kris MG, Basch E, Bohlke K, Barbour SY, Clark-Snow RA, Danso MA, Dennis K, Dupuis LL, Dusetzina SB, et al: Antiemetics: American society of clinical oncology clinical practice guideline update. J Clin Oncol 35: 3240-3261, 2017.

18. Dilruba S and Kalayda GV: Platinum-based drugs: Past, present and future. Cancer Chemother Pharmacol 77: 1103-1124, 2016.

19. Innocenti F, Schilsky RL, Ramírez J, Janisch L, Undevia S, House LK, Das S, Wu K, Turcich M, Marsh R, et al: Dose-finding and pharmacokinetic study to optimize the dosing of irinotecan according to the UGT1A1 genotype of patients with cancer. J Clin Oncol 32: 2328-2334, 2014.

20. Henricks LM, Opdam FL, Beijnen JH, Cats A and Schellens JHM: DPYD genotype-guided dose individualization to improve patient safety of fluoropyrimidine therapy: Call for a drug label update. Ann Oncol 28: 2915-2922, 2017.

21. Relling MV, Gardner EE, Sandborn WJ, Schmiegelow K, Pui $\mathrm{CH}$, Yee SW, Stein CM, Carrillo M, Evans WE and Klein TE; Clinical Pharmacogenetics Implementation Consortium: Clinical pharmacogenetics implementation consortium guidelines for thiopurine methyltransferase genotype and thiopurine dosing. Clin Pharmacol Ther 89: 387-391, 2011.

(i) (2) This work is licensed under a Creative Commons Attribution-NonCommercial-NoDerivatives 4.0 International (CC BY-NC-ND 4.0) License. 